http://periodicos.uefs.br/index.php/acordasletras/index

dit http://dx.doi.org/ 10.13102/cl.v19i3.2043

\title{
Gênero textual carta e ensino: considerações sobre a tradição epistolar
}

\section{Textual genre teaching letter: considerations about the epistolary tradition}

\author{
Elane Santos e Santos* \\ Universidade Estadual de Feira de Santana \\ Feira de Santana, Bahia, Brasil \\ Gutemberg Magalhães Oldack Barbosa** \\ Universidade Estadual de Feira de Santana \\ Feira de Santana, Bahia, Brasil \\ Rosana Carvalho Brito*** \\ Universidade Estadual de Feira de Santana \\ Feira de Santana, Bahia, Brasil \\ Zenaide de Oliveira Novais Carneiro ${ }^{* * * *}$ \\ Universidade Estadual de Feira de Santana \\ Feira de Santana, Bahia, Brasil \\ Mariana Fagundes de Oliveira Lacerda**** \\ Universidade Estadual de Feira de Santana \\ Feira de Santana, Bahia, Brasil
}

\begin{abstract}
Resumo: Neste artigo, apresentam-se algumas considerações acerca do gênero carta, enfocando seu percurso histórico, o conceito de tradições discursivas, estruturas que se repetem ao longo do tempo em um determinado contexto, e a possibilidade de empregar o gênero "carta do leitor" no ensino de língua.
\end{abstract}

Palavras-Chave: Gênero carta. Tradições discursivas. Ensino de língua.

\begin{abstract}
In this paper there are some considerations about the text genre letter, through the focus on its historical background and the concept of discursive traditions, structures that are repeated throughout time in a given context, and the possibility of using the genre "reader's letter" in the language teaching field.
\end{abstract}

Keywords: The genre letter. Discursive traditions. Language teaching.

*Estudante do Mestrado em Estudos linguísticos da Universidade Estadual de Feira de Santana, Feira de Santana, Bahia, Brasil. Bolsista CAPES. E-mail: lanysnts@gmail.com.

${ }^{* *}$ Estudante do Mestrado em Estudos linguísticos da Universidade Estadual de Feira de Santana, Feira de Santana, Bahia, Brasil. E-mail: gutho@yahoo.com.

***Estudante do Mestrado em Estudos linguísticos da Universidade Estadual de Feira de Santana, Feira de Santana, Bahia, Brasil. Bolsista FAPESB. E-mail: carvalho.rosana@hotmail.com.

${ }^{* * * *}$ Professora Plena do Departamento de Letras e Artes da Universidade Estadual de Feira de Santana, Feira de Santana, Bahia, Brasil. Membro Permanente do PPPGEL. E-mail: zenaide.novais@gmail.com.

${ }^{* * * * *}$ Professora Adjunta B do Departamento de Letras e Artes da Universidade Estadual de Feira de Santana, Feira de Santana, Bahia, Brasil. Membro Permanente do PPPGEL. E-mail: marianafag@gmail.com. 


\section{INTRODUÇÃO}

A escrita de cartas é uma tradição milenar. Há registros dessa prática desde a Antiguidade Clássica (DÓREA, 2012). No decurso do tempo, a escrita epistolar ${ }^{1}$ exibiu diversos matizes, até assumir seu perfil de correspondência pessoal, talvez sua acepção mais conhecida ${ }^{2}$, embora, enquanto instrumento de comunicação, esse gênero esteja em desuso, ao passo que emergem outras subcategorias, como as "cartas do leitor", processo de adaptação natural dos gêneros, que se modificam acompanhando as mutações nos diferentes campos da atividade humana ${ }^{3}$, como sugerido na frase em epígrafe. O papel comunicativo que, em outros tempos, era exercido pela carta pessoal, hoje é desempenhado por outros gêneros, como o e-mail. Para Marcotulio (2008), é possível pensar o gênero carta como um precursor do gênero e-mail. Contudo, esclarece o autor que "[...] a carta e o e-mail não podem ser agrupados em um mesmo gênero textual, dado que este último especializou-se em outro contexto social, o da denominada cultura eletrônica, e abarca funções comunicativas, intencionalidade e propósito diferentes [...]" (MARCOTULIO, 2008, p. 74-75).

Fato interessante é que a não utilização de cartas pessoais para fins comunicativos, hoje se faz acompanhar de um interesse crescente por esses materiais enquanto fonte de conhecimento sobre o passado, convertendo-os em importantes dados para pesquisas em diferentes áreas: na história, na religião, na linguística, na literatura etc.

Neste artigo, trata-se da possibilidade de utilizar uma subcategoria do gênero carta no ensino de língua, a "carta do leitor". Antes disso, a fim de possibilitar uma melhor compreensão sobre esse gênero, traça-se, na seção dois, seu percurso diacrônico, desde a Antiguidade clássica até assumir, no século XVIII, uma feição mais particular.

\footnotetext{
${ }^{1}$ Neste estudo, a palavra epístola é tomada como sinônimo de cartas pessoais de modo geral. Julga-se necessário esclarecer isso porque essa palavra, em alguns contextos, é utilizada em referência exclusiva às cartas bíblicas. Os dicionários Aulete digital e Aurélio digital, embora em alguns significados considerem carta como sinônimo de epístola, também reservam para essa última a significação de um tipo particular de carta, as cartas escritas pelos apóstolos às primeiras comunidades de cristãos.

${ }^{2}$ Com essa afirmação, não se ignora aqui as demais acepções de cartas: carta-convite; carta de demissão; carta de admissão etc., bem como sua funcionalidade.

${ }^{3}$ Bakhtin (2003:261), muito apropriadamente, associa os gêneros do discurso aos diferentes campos da atividade humana. Segundo o autor, os gêneros do discurso "refletem as condições específicas e as finalidades de cada referido campo [os campos da atividade humana] não só por seu conteúdo (temático) e pelo seu estilo da linguagem, ou seja, pela seleção dos recursos lexicais, fraseológicos e gramaticais da língua mas, acima de tudo, por sua construção composicional". Depreende-se dessa assertiva a concepção de gênero do discurso do autor: tipos relativamente estáveis de enunciados, que se definem pelo conteúdo temático, pelo estilo e pela construção composicional. Não se deterá aqui sobre a discussão mais aprofundada dos gêneros do discurso. Para os objetivos desse trabalho, é suficiente conhecer essa noção de gênero.
} 


\section{DAS CARTAS DE COMÉRCIO AO E-MAIL: AS TRANSMUTAÇÕES DO GÊNERO CARTA}

Segundo Dórea (2012, p. 54), “Os primeiros registros referentes à tradição da epistolografia no Ocidente foram encontrados na Antiguidade Clássica e, em particular, entre um grupo de filósofos gregos [...]". Pessoa (2002) explica que, nessa época, as cartas funcionavam como jornais, as cartas públicas, que passam de mão em mão difundindo notícias. Essa funcionalidade do gênero se estenderia através dos séculos. Dórea (2012) comenta que, desde o início, os mais variados documentos eram escritos na forma de cartas. Explica o autor que, além de adotadas para comunicação interpessoal:

As cartas, entre outros aspectos, eram usadas como instrumentos de cunho administrativo e político, por chefes de Estado. Podiam assumir a faceta de relatório burocrático, contendo informações variadas, inclusive comerciais. Quando tomavam a feição de carta aberta, dotavam de caráter público pontos de vista individuais ou de grupos. Também passou a ser comum, em certa época, o uso de cartas privadas com conteúdo informativo, a ponto de reconhecer-se, particularmente nos séculos XVI a XVIII, que elas circulavam com regularidade que chegavam a funcionar como uma espécie de jornal embrionário (DÓREA, 2012, p. 55).

Desde a Antiguidade, muitos tratados foram elaborados na tentativa de uniformizar o gênero carta. Segundo Tim (2005 apud Marcotulio, 2008), o mais antigo tratado de que se tem conhecimento é o de Demétrio, que provavelmente foi escrito entre os séculos I a.C. e II d.C. O autor acrescenta que a expansão das relações comerciais nessa época elevou a circulação de cartas pela Península Ibérica.

Pessoa (2002) informa que, na Idade Média, na Europa (entre os anos 800 e 1400), a prática epistolar era exercida, sobretudo, para troca de informações via mensageiros, sendo muito empregada também pelos imperadores e pelo papa. No século XIV, a troca de correspondências particulares entre os místicos para compartilhar experiências religiosas e espirituais íntimas contribuiu para difusão da prática da escrita privada. Essa difusão, por sua vez, representou outro avanço: a produção de cartas nas diversas línguas locais, já que, até então, as cartas eram escritas apenas em latim. Nessa época, a circulação de cartas é ampliada ainda pelo comércio na Itália setentrional, instaurando-se um sistema embrionário de trocas de correspondências. Mas, ainda predominava a circulação das cartas públicas, como espécies de jornais. Sobretudo a nobreza exercitava a escrita de cartas nesse período.

No século XVII, as cartas assumem uma dimensão literária ${ }^{4}$. As práticas epistolares da França influenciavam outros países europeus. Intensificam-se as trocas de cartas de amor, que divulgavam poemas épicos com exaltação de heróis. Pessoa (2002) comenta que o caráter intimista dessas cartas contribuiu para a difusão da prática de escrita de

\footnotetext{
${ }^{4}$ Sobre a utilização das cartas nos diversos movimentos literários no Brasil, vê Dórea (2012). O autor apresenta o percurso do gênero nos vários momentos da literatura brasileira, desde Manuel da Nóbrega (1517-1570), até os autores modernistas. O interesse maior de análise do autor são as cartas do escritor feirense Eurico Alves Boaventura.
} 
cartas privadas, que irá se consolidar no século XVIII, quando a carta "ganha um novo significado, passando a constituir numa espécie de telefone da época" (PESSOA, 2002, p. 199). Ao observar a funcionalidade do telefone para a comunicação hoje, é possível observar que a difusão das cartas pessoais no século XVIII foi bastante extensa. Nesse século, novamente a literatura encontrará no gênero epistolar excelente suporte. Trata-se do desenvolvimento do romance epistolar, quefoi consequência do "hábito de escrever cartas" (ibid.).

Sobre a documentação epistolar em Portugal, Pessoa (2002, p. 200) esclarece que, além de ser uma das mais antigas da tradição portuguesa, "Está diretamente relacionado com a criação do tabelionato e a chancelaria, instituições básicas na formação da administração e burocracia portuguesas", o que pode ser um indicativo de que vários documentos eram escritos na forma de carta. As cartas terão especial interesse em Portugal na época das grandes navegações, através dos relatos dos viajantes. No século XVI, no início da colonização do Brasil, será através do gênero epistolar que os viajantes informarão ao rei de Portugal as boas novas acerca do "descobrimento" das terras brasílicas. O documento mais antigo escrito no Brasil é também uma carta e remonta exatamente aos idos de 1500 quando os portugueses aportam no país. Trata-se da Carta do descobrimento, datada de $1^{\circ}$ de maio de 1500, escrita por Pero Vaz de Caminha.

Em relação à prática de escrita de cartas no Brasil, Pessoa (2002) comenta que:

Parece que o que aconteceu no Brasil do século XIX é uma reprodução em parte do que acontecera na Europa no século XVIII. Se o romance surge no XVIII europeu, ele surge no XIX No Brasil; se a carta se populariza na Europa no XVIII, ela se populariza no Brasil no XIX; se o jornal cresce na Europa do XVIII, no Brasil isto se dá no século XIX (PESSOA, 2002, p. 202).

Percorreu-se esse percurso aqui a fim de esclarecer que a carta pessoal, tal qual é conhecida hoje, assumiu suas feições no decurso do tempo, até ter seu uso difundido no século XVIII em Portugal e no século XIX no Brasil. No caso brasileiro, essa tradição possivelmente teve grande funcionalidade também no século XX, pelo menos em áreas onde os aparatos tecnológicos tardaram a chegar. O corpus constituído por Santiago (2012), composto por 91 cartas pessoais escritas por 43 lavradores de áreas rurais dos municípios baianos de Riachão do Jacuípe, Conceição do Coité e Ichu, ao longo do século XX (19062000), é um forte indício disso. Essas cartas foram trocadas entre familiares e amigos, a fim de enviar e obter notícias uns dos outros, bem como solicitar favores, quase sempre relacionados ao trabalho no campo desenvolvido por esses sertanejos. Há ainda correspondências trocadas entre namorados e cartas de pedido de casamento. A circulação desse tipo de correspondência não deve ter sido exclusividade dessas três localidades. É possível que em outras áreas do estado, e mesmo em outros estados e regiões do país, outros grupos que estiveram às margens do processo tecnológico, que começa a emergir no Brasil no século XX, também tenham exercitado a prática epistolar ao longo desse século.

Se, por um lado, o desenvolvimento e o aperfeiçoamento dos meios de comunicação de massa, com o advento das novas tecnologias da informação e 
comunicação, que possibilitam maior comodidade e agilidade na comunicação interpessoal, dispensam a tradição epistolar;por outro lado, essa tradição se mantém bastante viva enquanto fonte disponível para o estudo do passado sob diversas óticas. As 91 cartas pessoais editadas por Santiago (2012), por exemplo, são de extrema relevância, dentre outros aspectos, para os estudos linguísticos. Importância que se amplia quando se considera que são produtos gráficos de pessoas semialfabetizadas, que favorecem a presença de marcas da oralidade na escrita e podem fornecer indícios do que teria sido o português popular da região do semiárido baiano compreendida pelos três municípios de procedência dos redatores.

Entendendo que a compreensão do conceito de tradições discursivas é relevante para o conhecimento do gênero carta, na seção seguinte, aborda-se esse conceito.

\section{TRADIÇÕES DISCURSIVAS}

O estudo sobre as tradições discursivas (doravante TD) vem sendo muito debatido ${ }^{5}$ entre os pesquisadores no campo da linguística, por conta do real significado das TD e o que poderia ser realmente considerado como TD. No estudo sobre o gênero carta, é importante reconhecer o que faz parte do gênero e o que seria uma tradição do período em que ele foi usado. Com isso, apresenta-se, neste artigo, o conceito e o reconhecimento do que seriam tradições discursivas presentes no gênero carta.

Kabatek (2006) aponta que a noção de TD se originou da linguística alemã, partindo dos conceitos de Eugenio Coserio sobre os três tipos de falar, que abordam a distinção entre: o falar geral, próprio a todos os seres humanos; o bistórico das línguas como sistemas de significação realizados ou atualizados no terceiro nível, sendo este, correspondente aos textos ou discursos concretos. Conforme o autor, o conceito de TD nasce dessa classificação e é ampliado, ele as define como:

Entendemos por Tradição Discursiva (TD) a repetição de um texto ou de uma forma textual ou de uma maneira particular de escrever ou falar que adquire valor de signo próprio (portanto é significável). Pode-se formar em relação a qualquer finalidade de expressão ou qualquer elemento de conteúdo, cuja repetição estabelece uma relação de união entre atualização e tradição; qualquer relação que se pode estabelecer semioticamente entre dois elementos de tradição (atos de enunciação ou elementos referenciais) que evocam uma determinada forma textual ou determinados elementos lingǘsticos empregados. (KABATEK, 2006, p. 512).

O autor afirma que uma TD é mais que um simples enunciado, se constitui de um ato linguístico que conecta um texto a uma realidade situacional, bem como relaciona um texto com outros textos da mesma tradição. Pessoa (2006) ressalta que a denominação "tradições discursivas" demonstra um lado pertencente à história dos textos. Esse lado

${ }^{5}$ cf. Kabatek (2006), o autor relata que há inúmeras pesquisas, de diversas orientações, que utilizam o termo tradições discursivas,e isso gera um certo conflito no entendimento desse novo paradigma. 
contempla um caráter histórico das línguas e se posiciona entre o universal e o individual. O autor aponta que as TD não nascem do nada, mas passam por alterações. Pessoa (2006) cita os estudos de Koch (1997) baseado em Wilhelm (1996), sobre as três formas de inovação das TD, sendo elas: inovação por diferenciação de tradições culturais, inovação por mistura de tradições culturais e inovação por convergência de tradições culturais. A primeira reflete a capacidade que a TD tem de se distinguir ao longo do tempo; a segunda demonstra que duas tradições que permaneceram diferenciadas ao passar do tempo, possibilita combinações que dão origem a uma nova tradição;e o terceiro caso situa duas tradições diferentes que desaparecem, transformando-se numa nova tradição.

\subsection{AS TRADIÇÕES DISCURSIVAS E O GÊNERO CARTA}

Sobre a importância das tradições discursivas no estudo do gênero carta, Marcotulio (2010), ao analisar a produção escrita do $2^{\circ}$ marquês do Lavradio no século XVIII, relata que as TD não são partes constituintes do gênero em si, no entanto, seriam microestruturas presentes ao longo do tempo e se tornaram relacionadas ao gênero carta, sendo utilizadas como formas permanentes dos moldes de escrita da época. O autor inclui as seções constitutivas do gênero carta como macroestruturas de análise, são estas: seção de contato inicial, núcleo da carta e seção de despedida. As estruturas encontradas nessas macrocategorias é que podem ser denominadas, conforme o autor, de tradições discursivas ou microestruturas. Sendo assim, será demonstrada, a partir do modelo de carta a seguir, a localização das macrocategorias e microcategorias, com base no estudo de Marcotulio (2010).

Figura 1 : Carta pessoal
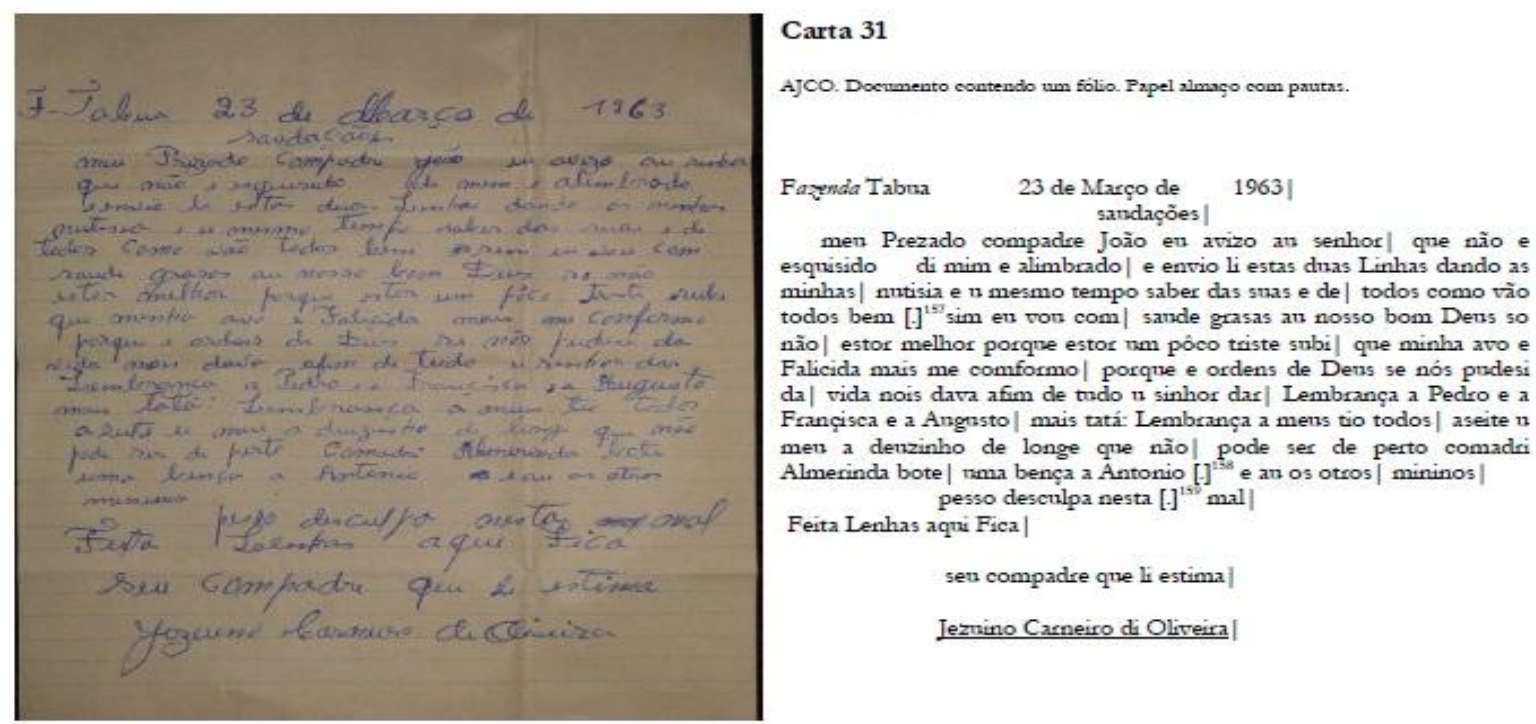

Fonte: Santiago (2012, p. 250). 
Sobre as macrocategorias do gênero carta, temos como primeira a seção de contato inicial, em que algumas informações podem ser vistas no cabeçalho, como mostra a figura 1, que retrata o local e a data (Faz̧enda Tabua 23 de Março de 1963). No corpo da carta ainda na seção de contato inicial pode-se observar também, a saudação inicial e a captação de benevolência (saudações | meu Prezado compadre João eu avizoau senhor| que não e esquisidodi mim e alimbrado|). O núcleo da carta ou corpo do texto, aponta o motivo pelo qual a carta foi escrita (e envio li estas duas Linhas dando as minhas | nutisia e u mesmo tempo saber das suas e de | todos como vão todos bem [.] sim eu vou com | saudegrasasau nosso bom Deus so não| estor melhor porque estor um pôco triste subi| que minha avo e Falicida mais me comformo | porque e ordens de Deus se nós pudesi da| vida nois dava afim de tudo u sinhor dar| Lembrança a Pedro e a Françisca e a Augusto| mais tatá: Lembrança a meus tio todos |). Na seção de despedidapode-se observar alguns elementos como saudação final, e a assinatura do remetente (u meu a deuzinho de longe que não| pode ser de perto comadri Almerinda bote| uma bença a Antonio [.] e au os otros| mininos| pesso desculpa nesta [.] mal|Feita Lenhas aqui Fica|seu compadre que li estima|Jezuino Carneiro di Oliveira).

A carta analisada faz parte do acervo Cartas de Sisal: Riachão do Jacuípe, Conceição do Coité e Ichu.Esta amostra foi editada por Santiago (2012) e traz cartas redigidas por escreventes baianos adultos, pouco escolarizados caracterizados como mãos inábeis (MARQUILHAS, 2000). Mesmo em se tratando de uma amostra diferente da utilizada no estudo de Marcotulio (2010), que retrata a escrita de um escrevente culto do século XVIII, pode-se perceber que a forma da escrita do gênero textual carta ou as macrocategorias se mantiveram. Sobre as microcategorias, o autor salienta que são formas cristalizadas, que possuem uma estrutura recorrente, e afirma que: "As tradições discursivas passam, obrigatoriamente, pelo processo de evocação, repetição, ritualização e posterior normatização/legitimação, atingindo assim, o estágio da fixação.” (MARCOTULIO, 2010:79). Sendo assim, ao analisar a amostra a que pertence a figura 01, nota-se a constante repetição das formas (Prezado compadre/comadre) na seção de contato inicial e na seção de despedida as formas (do seu compadre/comadre), podendo ser consideradas como tradições discursivas do período e do local em que foram escritas.

Com essa breve análise, percebe-se que as tradições discursivas são importantes para o entendimento das formas que aparecem nas cartas, pois relatam as regras sociais de determinado período. Da mesma forma, o estudo das macrocategorias, que estabelecem e categorizam o gênero carta, são essenciais para compreensão desse gênero.

\section{O GÊNERO CARTA E O ENSINO DE GÊNEROS DISCURSIVOS}

A partir do surgimento e crescimento da chamada era digital e de toda uma tecnologia especialmente voltada às possibilidades de interação social, tudo se tornou mais acessível para os bilhões de usuários dos meios de comunicação disponíveis. Com isso, a "carta pessoal" perdeu seu espaço enquanto instrumento de comunicação largamente utilizado no passado. 
Hoje, a carta praticamente sobrevive como a "carta do leitor", ainda muito usada para ser enviada a jornais e revistas que circulam periodicamente, para questionar, discutir ou elogiar notícias publicadas.

Com a Lei de Diretrizes e Bases da Educação (LDB, 1996) e os Parâmetros Curriculares Nacionais (PCNs, 1997), o trabalho desenvolvido em Língua Portuguesa abandona seu foco tradicional apenas no aspecto gramatical e se amplia no que diz respeito ao trato com o texto, enfatizando assim o estudo dos gêneros discursivos.

Tendo como base as orientações da LDB e dos PCNs, trabalhar a Língua Portuguesa, em sala de aula, passou a necessitar de ações em que o uso real da língua estivesse presente: usando o texto como base para tudo, inclusive o ensino de gramática normativa, já que a língua se mostra no texto bem próxima de como é em uso. Assim, tanto para o ensino como para pesquisa, Bakhtin (2003:308) diz que "só o texto pode ser o ponto de partida". Tal afirmação é ampliada por Geraldi (1997:135), quando diz que o texto precisa ser visto como "o ponto de partida (e ponto de chegada) de todo processo de ensino/aprendizagem da língua”.

A partir desses avanços, a língua precisou ser repensada como modelo de interação, e aí surgem os gêneros textuais para promovê-la. Isso significa que, a partir dessas práticas com o texto, pode-se criar meios que possibilitaram os liames para que a língua se manifestasse a partir dos diversos gêneros, como afirma Marcuschi (2008)

Os gêneros textuais são os textos que encontramos em nossa vida diária e que apresentam padrões sociocomunicativos característicos definidos por composições funcionais, objetivos, enunciativos e estilos concretamente realizados na integração de forças históricas, sociais, institucionais e técnicas. [...] Alguns exemplos de gêneros textuais seriam: telefonema, sermão, carta comercial, carta pessoal, romance, bilhete, reportagem, aula expositiva, reunião de condomínio, notícia jornalística, horóscopo, receita culinária, bula de remédio, lista de compras, cardápio de restaurante, instruções de uso, inquérito policial, resenha, edital de concurso, piada, conversação espontânea, conferência, carta eletrônica, bate-papo por computador, aulas virtuais e assim por diante. Como tal, os gêneros são formas textuais escritas ou orais bastante estáveis, histórica e socialmente situadas. (MARCUSCHI, 2008, p. 155).

E, sendo assim, são trabalhados igualmente a oralidade, a leitura e a escrita, em uma perspectiva na qual o aluno se aproprie do seu lugar de sujeito com domínio discursivo, para ocupar, agora preparado, o seu espaço na tecitura social, já que toda a comunicação se dá através de textos orais ou escritos, apresentados a partir de um ou vários gêneros. Conforme Dolz, Noverraz e Schneuwly (2004), a ponte entre as atividades do aluno e as práticas de linguagem serão sempre os gêneros discursivos. Ainda afirmam que, para o ensino da textualidade e o domínio da produção da linguagem, é necessário partir dos gêneros aprendidos nas aulas, ou seja, as estratégias de ensino precisam se alicerçar sobre os gêneros. Considerando isso, apresenta-se, a seguir, uma proposta de sequência didática para o trabalho com o gênero discursivo "carta do leitor", em sala de aula. 


\subsection{SEQUÊNCIA DIDÁTICA PARA TRABALHAR O GÊNERO "CARTA DO LEITOR"}

Com essa sequência didática, propõe-se um trabalho, com alunos do $1^{\circ}$ ano do ensino médio, de início, em 15 horas/aula, com o gênero carta do leitor, por se tratar de um exemplo que, sendo público, aproxima-se mais de realidades sociais de uso da língua.

Procurou-se contemplar os pontos propostos pelos PCNs - oralidade, leitura, produção de texto e análise linguística - para o desenvolvimento das competências linguístico-discursivas dos alunos. Para tanto, será considerado o aparato teóricometodológico, para construção de uma "sequência didática" (SD), elaborado por Dolz, Noverraz e Schneuwly (2004:96) que trabalham diretamente com o ensino da leitura, produção e exposição de gêneros orais ou escritos em vários ambientes.

Os autores da SD trazem-na como uma proposta planejada de ensino-aprendizagem voltada às práticas da leitura, da oralidade e da escrita, para qualquer nível de ensino, e que tenha bem definida cada etapa da figura a seguir:

Figura 2: Proposta de ensino-aprendizagem.

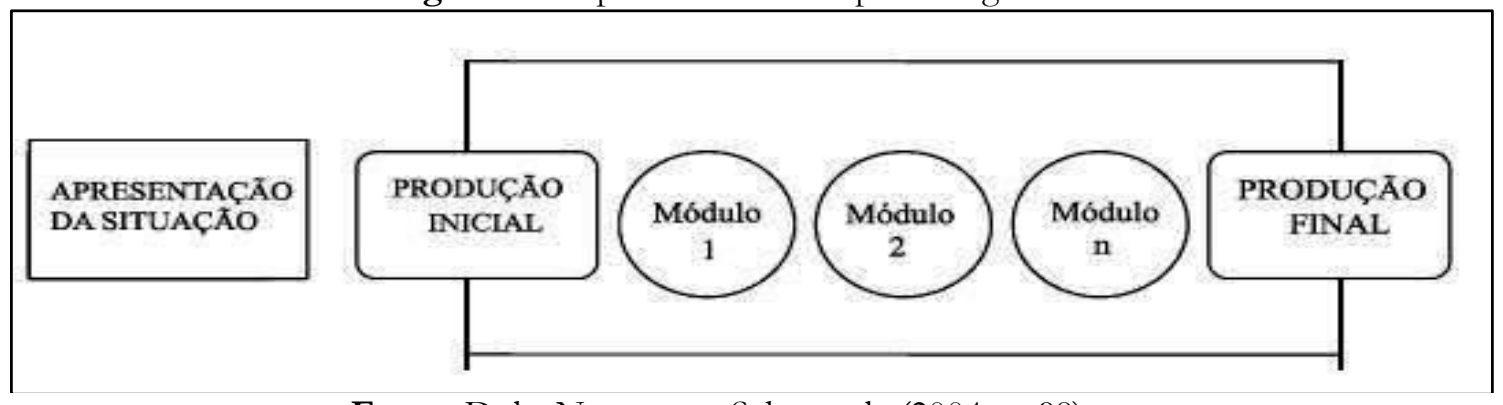

Fonte: Dolz, Noverraz e Schneuwly (2004, p. 98).

Tomando como base a figura 2, as atividades começarão nas três primeiras aulas, em que será cumprido o ponto 1 que seria a "apresentação da situação". Esse primeiro momento consiste em uma exposição detalhada sobre a SD e como será desenvolvida pelos alunos durante as aulas que serão utilizadas para tal; o que será feito em cada ponto até o final; a construção de uma agenda com datas e atividades a serem desenvolvidas em cada momento; a divisão de grupos de trabalho; além da apresentação de modelos do gênero a ser trabalhado, através de cartas do leitor enviadas e publicadas. Ainda nesse item 1, algumas perguntas deverão ser respondidas. A saber: i) qual gênero será estudado; ii) qual a finalidade dessa produção; iii) para quem é dirigido este texto.

Em um segundo momento, que necessitará de mais duas aulas, aplica-se a sequência proposta para o ponto 2, chamado de "produção inicial". Aqui, serão produzidos textos do gênero trabalhado para, após correção, ser percebido o que o aluno já sabe e o que não sabe sobre a produção desse gênero em questão, para, a partir dessas observações dos resultados obtidos, serem feitos os devidos ajustes das etapas seguintes. 
No ponto 3, chamado de "módulos", serão utilizadas mais seis aulas, duas para cada módulo, aproximadamente. Este momento consiste em realizar atividades diversas, preparadas a partir das dificuldades observadas na primeira produção dos alunos, principalmente nas atividades de leitura e análise linguística. Aqui, há a possibilidade de convidar um especialista externo para bater um papo com os alunos sobre gêneros e, especialmente, o trabalhado. Nesses módulos, a escrita e reescrita dos textos são de imprescindível importância para levar os alunos à etapa posterior.

No ponto 4, momento da "produção final", serão usadas a últimas quatro aulas restante, do total das quinze previstas no início. Será o momento em que os alunos irão por em prática tudo o que aprenderam durante os "módulos", fazendo a produção final de uma "carta do leitor", a partir de uma dada reportagem de uma revista ou jornal. E assim o professor terá uma visão de quais resultados foram alcançados durante todo o processo da SD.

Propõe-se aqui a adição de um “ponto 5". Este momento implicará em fazer a circulação do gênero a partir da publicação das produções dos alunos, no espaço escolar, através de murais, painéis e rodas de debates para trabalhar a oralidade e o poder de argumentação assimilado, durante as leituras e discussões feitas nos módulos.

Sabe-se que os alunos precisam cada vez mais ser preparados para lerem e identificarem o tipo e o gênero discursivo que se apresentam no texto lido. Assim, seguese o trabalho na formação de leitores competentes e produtores de textos orais e escritos de qualidade, já que essas ações são conhecidas como pontuais da escola.

\section{CONSIDERAÇÕES FINAIS}

Neste artigo, discorreu-se acercada constituição do gênero textual carta, do seu percurso histórico, do paradigma das tradições discursivas e sobre a possibilidade de trabalhar com esse gênero em sala de aula.

A escrita de cartas é uma tradição milenar, instituída desde a Antiguidade Clássica para fins comunicativos, administrativos, políticos e religiosos.No Brasil, a carta pessoal foi assumindo sua forma ao decorrer do tempo, primeiramente teve o seu uso difundido em Portugal, no século XVIII, e no século seguinte no Brasil, sendo muito utilizada também no século XX, como principal meio de comunicação nas áreas rurais do território brasileiro.

Sobre as tradições discursivas, viu-se que se tratam de fórmulas presentes no gênero carta, que se repetem,retratando o contexto comunicativo e os padrões sociais do período em que foram escritas, sendo relevante o conhecimento desse tema, principalmente para os estudos linguísticos envolvendo o gênero carta. Com o avanço da tecnologia, as cartas pessoais já não são mais tão utilizadas para fins comunicativos. Por outro lado, cresce o interesse de diversos campos de estudo (religioso, linguístico, histórico, educativo etc.) por esses materiais. No ensino de língua portuguesa, as cartas constituem excelente fonte para exploração de aspectos da língua. Neste artigo, abordou-se a funcionalidade desse gênero no ensino de língua, mais especificamente a "carta do leitor", gênero bastante difundido. 


\section{REFERENCIAS}

BAKTHIN, M. Estética da criação verbal. Trad. Paulo Bezerra. 4 ed. São Paulo: Martins Fontes, 2003.

BRASIL. MEC. Parametros Curriculares Nacionais: Língua Portuguesa, Ministério da Educação e do Desporto, Secretaria da Educação Fundamental, Brasília: 1997.

BRASIL. Ministério de Educação e Cultura. LDB - Lei no 9394/96, de 20 de dezembro de 1996. Estabelece as diretrizes e bases da Educação Nacional. Brasília: MEC, 1996.

DICIONÁRIO AULETE DIGITAL. Disponível em: <http://www.aulete.com.br/bomba>. Acesso em 27 jul. 2017.

DICIONÁRIO AURÉLIO DIGITAL. Disponível em: $<$ http://dicionariodoaurelio.com/bomba>. Acesso em 27 jul. 2017.

DÓREA, Juraci. Cartas de Eurico Alves: fragmentos da cena modernista. Feira de Santana: UEFS Editora, 2012.

DOLZ, J.; NOVERRAZ, M.; SCHNEUWLY, B. Sequências Didáticas para o Oral e a Escrita: Apresentação de um Procedimento.In: DOLZ, J.; SCHNEUWLY, B. Gêneros orais e escritos na escola. Trad. Roxane Rojo e Glaís Sales Cordeiro. Campinas: Mercados das Letras, 2004.

GERALDI, João Wanderley. Da redação à produção de textos. In: GERALDI, J.W.; CITELLI, B. (orgs.) Aprender e ensinar com textos de alunos. Vol. 1. São Paulo: Cortez, 1997.

KABATEK, Johannes. Tradições discursivas e mudança lingüística. In: LOBO, Tâniaet. al. (Org.).Para a bistória do português brasileiro. Salvador: EDUFBA, 2006. v. 6, t. 2. p. 505527. Disponível em:

$<$ https://repositorio.ufba.br/ri/.../ri/.../Para $\% 20 \mathrm{a} \% 20$ historia $\% 20 \% 20$ Tomo $\% 20 I I \_R$ I.pdf $>$.

Acesso em: 28 jul. 2017.

MARCOTULIO, Leonardo Lennertz. A preservação das faces e a construção da imagem no discurso politico do marquês do Lavradio: as formas de tratamento como estratégias de atenuação da polidez linguística. 2008. 215 f. Dissertação (Mestrado em linguística) Universidade federal do Rio de Janeiro, Rio de Janeiro, 2008.

MARCOTULIO, Leonardo Lennertz. Lingua e história: o $2^{\circ}$ marquês do Lavradio e as estratégias linguísticas da escrita no Brasil colonial. Rio de Janeiro: Ítaca, 2010.

MARCUSCHI, L. A.. A Produção textual, análise de gêneros e compreensão. 3. ed. São Paulo: Parábola, 2008. 
MARQUILHAS, Rita. A faculdade das letras: Leitura e escrita em Portugal no séc. XVII. Lisboa: Imprensa Nacional-Casa da Moeda, 2000.

PESSOA, Marlos de Barros. Da carta a outros gêneros textuais. In: DUARTE, Maria EugênciaLamoglia; CALLOU, Dinan (Org.). Para a história do português brasileiro: notícias de corpora e outros estudos. v.4. Rio de Janeiro: Faculdade de Letras da UFRJ/FAPERJ, 2002.

PESSOA, Marlos de Barros. Transformação da tradição discursiva "requerimento": séculos XVIII e XX. In: LOBO, Tânia et. al. (Org.). Para a história do português brasileiro. Salvador: EDUFBA, 2006. v. 6, t. 2. p. 505-527. Disponível em: $<$ https://repositorio.ufba.br/ri/.../ri/.../Para $\% 20 \mathrm{a} \% 20$ historia $\% 20 \% 20$ Tomo\%20II_R I.pdf>. Acesso em: 28 jul. 2017.

ROJO, Roxane. A prática de linguagem na sala de aula:praticando os PCNs. Campinas: Mercado de Letras, 2000.

SANTIAGO, Huda da Silva. Um estudo do português popular brasileiro em cartas pessoais de "mãos cândidas" do sertão baiano. 2012. 2v. 256f. Dissertação (Mestrado em Estudos Linguísticos) -Universidade Estadual de Feira de Santana, Feira de Santana, 2012. Disponível em: $<$ https://issuu.com/prohpor/docs/disserta___o_huda_santiago_2012>. Acesso em: 3 jun. 2017.

Recebido em: 15/07/2018

Aprovado em: 03/11/2018

Publicado em: 31/12/2018 